\section{Scientific classic of history}

\section{J. D. North}

Copernicus: On the Revolutions of the Heavenly Spheres. Translated by A. M. Duncan. Pp. 328. (David and Charles: Newton Abbot and London; Barnes and Noble/Harper and Row: New York, 1976.) $£ 12.50$.

Just as in the Middle Ages the Bible and Liturgy were encased in Latin for the almost exclusive use of the priesthood, so in our own time most of the scientific classics of history remain either untranslated or-what is worsebadly translated. It should not be necessary to plead the case for a trans- lation of the De Revolutionibus by Copernicus. The inadequacies of that prepared by Charles Glenn Wallis, and published in the series Great Books of the Western World, are easily exaggerated, but too numerous to make it an acceptable student edition. Dr Duncan's new translation is not only better, but it has the virtue of being separately available-that is, without an obligation to purchase the other 53 volumes of a collection.

Dr Duncan's style is modest, simple, and direct. His introduction could be readily understood by any sixth-former. The notes and introduction are not very long or profound, but neither are they likely to frighten away the inexpert reader. The heliocentric idea is kept to the centre of the commentary, where it belongs, psychologically if not technically. The simplicity of the commentary is, however, occasionally misleading -as when the so-called theory of trepidation is considered, and as when modern disputes over Copernicus' Aristotelianism and the reality of the

spheres are deftly swept under the carpet. Copernicus's conservatism in the use of Ptolemaic methods and parameters is stressed, but Copernicus is represented as having made an advance on Ptolemy by the introduction of systematic observational tests of his model. The truth of the claim-simply because it is made so briefiy in the introduction-is itself difficult to decide, but there are many who will find traces of special pleading in it, at least as far as it concerns Ptolemy.

The notes to the translation are slight and sparse, and the bibliography at the end even sparser. There are no indexes. The translation occupies almost ninetenths of the book, and it is of course by this that the volume must primarily be judged. Speaking generally, the version is accurate and readable, and if it were possible to review the translation at pedantic length, most of my own objections would concern matters of taste rather than of substance. For example, out of kindness to the modern reader, commutatio is rendered as "parallax". On the other hand obliquatio is translated by the archaic "obliquation". I am not convinced that the flavour of the original is kept when causa is translated as "law" in such a context as Osiander's preface, as here: ". . . this subject [astronomy] is completely and simply ignorant of the laws which produce apparently irregular [planetary] motions". And I think that "correction" is an insufficiently specific rendering of prosthasphaeresis. But any careful reader of the text will not find much difficulty with technical terms.

The book is attractively produced at what must now be reckoned a very reasonable price, kept down by the expedient of printing the many figures in wide central margins. These are occasionally a trifle too small to be easily read, and are taken from the 1617 edition.

It must be noted that Dr Duncan's translation will soon be joined by another, produced by Edward Rosen for the Polish edition. The cost of the latter is likely to outstrip that of the David and Charles production, which is therefore more likely to reach the general reader, at whom the introduction and notes are aimed. Further comparison must be left until the Rosen translation is published. It is a moot point whether the market can take both versions, but English-speaking fans of Copernicus, working on the surgeon's principle that an extra opinion is always valuable, will no doubt insist that you cannot have too much of a good thing.

J. D. North is Assistant Curator of the Museum of the History of Science, University of Oxford, UK. 